secutive pages as in the conventional textbook. Each unit ends with a multiple-choice question designed to test the reader's grasp of the information it contains and different page references accompany the various proffered solutions. The right answer leads to the next in the sequence. Incorrect responses, on the other hand, are followed by additional explanation and factual repetition appropriate to the particular error, after studying which the reader is required to attempt the question again. Not until he chooses correctly is he allowed to proceed with the main learning sequence. The book as a whole is organised into six chapters, each of which is followed by a revision summary and by a further set of tests; by comparing his answers to the latter with those given in a key at the back of the book, the student can assess his overall progress after completing each of these major stages.

This technique, known as the branching method of programmed learning, is gaining increasing acceptance in the fields of general education and industry either in the present scrambled textbook form or as mechanically presented by means of so-called teachingmachines. Preliminary evidence suggests that learning in this way may be both quicker and more efficient than by traditional methods (including ordinary reading), perhaps the most significant feature of the new approach being the constant active participation demanded of the learner. Being self-paced, it is also economical of time; brighter students avoid the sometimes lengthy repetition required by their weaker brethren and with it the tendency to become bored or impatient.

Though it seems certain that programmed learning will in the future be usefully applied also to medical education, the present volume, which is the first in a series of three, is probably too elementary to have much appeal for either doctors or medical students. It is based on material taught to students in natural science at Michigan State University but seems hardly to go beyond the genetics of ' $A$ ' level biology courses in this country. It there are still medical men who lack all knowledge of basic Mendelian concepts, however, this beautifully produced paperback will certainly provide them with a stimulating and effective means of repairing the omission. Medical educationalists, moreover, will study with great interest this new method of textbook presentation.

\section{Teaching the Severely Subnormal}

A handbook for the staff of Junior Training Centres. Edited by E. B. McDowall. Pp. viii + 128. London: Edward Arnold. 1964. 20s.

This manual is designed primarily to be of use to those who are beginning to work in Junior Training Centres. The three contributors, Audiologist, Chief Speech Therapist, and Warden Supervisor of a Training Centre and Hostel, all work in Hampshire, where Dr. McDowall is the Principal Medical Officer for Mental Health.

Any book of this kind must inevitably strike a balance between the risk of being too technical and the dangers of over-simplification. However, staff of training centres need more than a smattering of technical information. Trainees are more difficult to teach, and more often have other handicaps than ordinary children. Perceptual difficulties are not mentisned, nor is the technical problem of attention span. Autism is dismissed in a sentence. Chapter eight deals with physical handicaps in $\mathbb{D}$ eight pages and includes a section on deafness. The special senses are so fundamental to learning that - they deserve separate consideration and more care- $\overrightarrow{\text { fon }}$
ful presentation.

The last four chapters and appendix may wello interest many who advise the parents of mentally으 subnormal children as in them is described the $\overline{\bar{s}}$ sort of education available in most training centres today (pace Professor Clarke). The text is besto where it has a firm basis of local experience.

Perhaps this subject will be revolutionised when repetitious, self-adjusting teaching machines are $\overrightarrow{0}$ programmed to the needs of mongols and thosewith particular forms of cerebral damage.

\section{Viruses of Vertebrates}

SIR CHRISTOPHER ANDREWES, M.D., F.R.C.P., F.R.S. Pp. xi + 401. London: Baillière, Tindall $\overrightarrow{-}$ and Cox. 1964. 63s.

This book breaks new ground in providing an $\vec{i}$ exhaustive catalogue of the properties of viruses affecting man and other vertebrates. It is an exciting $\sigma^{\circ}$ book for any postgraduate interested in infections응 for he will undoubtedly discern and be touched by the author's basic research experience, his wide ${ }_{c}$ knowledge and deep cultural attainments; this only@ too rare combination makes this book a joy to read.

Just as we learned to regard bacteria as Gram- ص positive or Gram-negative, so is it new fundamental to try to understand viruses as predominantly RNA $\vec{C}$ or DNA. This book is divided, according to this plan, into sections on the RNA viruses, the DNA viruses, the agents containing both these types of nucleic acids, and a section on viruses which are hitherto unclassified by this scheme. Another helpful feature of viruses is the presence or absence of an outer envelope enclosing a more rigid structure. Sensitivity to inactivation by ether, chloroform or $\stackrel{\mathbb{Q}}{\varrho}$ desoxycholic acid is fairly well correlated with this feature and this provides another means of sub-o dividing and grouping viruses. A third important 3 property of viruses is the possession of cubical or $\bar{P}$ helical symmetry in the arrangement of proteino subunits. These and other characters are basic criteria for the reclassification of viruses, which the $\frac{0}{3}$ author presents lucidly and convincingly. The author also provides a secure foundation upon which a still more ambitious and comprehensive classification of viruses can be built as fresh knowledge $\delta$ accrues in the years to come.

The appeal of this book is not limited to the

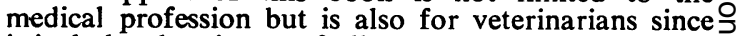
it includes the viruses of all vertebrates. They should $D$ turn to it, as bacteriologists turn to Bergey's manual, to help in the indentification of an unknown virus which may be encountered.

It is hoped that Sir Christopher Andrewes will ${ }^{\circ}$ guide this outstanding book through several editions. 0

Physiological Problems In Space Exploration

Edited by James D. HaRdy. Pp. ix $+333 . \stackrel{\varrho}{\complement}$ Springfield, Illinois: Charles C. Thomas. 1964. $\$ 12.50$.

This is a most fascinating book packed with scientific data concerning the physiology of space $\frac{\vec{C}}{\mathbb{D}}$ travel. It will be of inestimable value to those work- $\Omega$ 
ing in this field and every medical scientist will find it full of interest. Professor Hardy, the Editor, is the Professor of Physiology at Yale and six other distinguished scientists including Professor Brobeck (Professor of Physiology at the University of Pennsylvania) and Professor Halzberg (Professor of Pathology at the University of Minnesota) have contributed chapters. Every aspect receives consideration; food and gaseous requirements, the problems of temperature, acceleration, weightlessness, isolation and perception and the sum total is a notable addition to scientific literature. In his foreword Professor Hardy points out that space engineers have from the outset endeavoured to provide for the astronaut the same environment that he has on earth but he stresses the importance of the role of physiologists and psychologists in defining the limits of human performance and survival in the stress of long periods of loneliness, extremes of heat and cold, high energy radiations, acceleration and high velocity and the vacuum of inter-planetary space. The mass of references reflect the enormous literature on space travel that has already accumulated. It is difficult to select any part of the book for especial mention as the standard of it all is so high, but the chapters on gaseous requirements, on temperature and on isolation and disorientation were of particular interest to the reviewer. In the last of these Dr. Randall Chambers from the U.S. Naval Air Development Center points out the importance of careful selection and training of astronauts, and of keeping them occupied during their flight.

\section{Problems of Biochemistry of the Nervous System}

Edited by A. V. Palladin. Translated from the Russian. Pp. xii +330 , illustrated. Oxford, London, New York and Paris: Pergamon Press. 1964. 80s.

This work is the English translation of the Russian book giving the contributions to a symposium held at Kiev in 1957 under the chairmanship of Professor A. V. Palladin. It is therefore highly technical in nature and can appeal only to the specialist. Such books generally have only a limited useful life, but since this book sheds light on the whole Russian approach to neurobiochemistry its interest may be greater than the seven year delay in publication might imply.

It is clear that many of the authors are dominated by the principles laid down by Pavlov, and that this affects the practice of medicine in Russia. We are told that sleep therapy is extensively used in Soviet clinics, although, rather tantalisingly, the actual uses are not stated. The objectives of the workers in this field are defined by Professor Palladin. "The task of functional biochemistry of the brain is to reveal correlations between specific functions of the nervous system and the chemical structure and metabolism of the nervous tissue . . " Some might quarrel with this aim, but we cannot ignore the results of the investigations which are presented. The functions studied however are mainly limited to metabolism of very simple substances such as glucose, ammonia, pyruvic acid, ATP etc., and under the influence of stimulation and depression of the brain by drugs, low temperature, and Pavlovian conditioned reflexes. Consequently, although much interesting factual matter is to be found, and generally the techniques used are advanced, many might think these methods too crude to advance the stated aims. Nevertheless the authors' attempt to correlate their results with function. Thus, we arrive at statements such as (p. 151) "The ammonia which forms when the drug is injected excites the central nervous system. Due to the continued action of ammonia this excitation becomes an inhibition which is accompanied by an increased amount of ammonia, due to its fixation into glutamine so characteristic of the inhibitory state". It is difficult to see just what is fact and what is deduction or assumption.

The translator and editors are to be congratulated upon having given us an English text which is both clear and agreeable in style.

\section{NEW EDITIONS}

\section{Practical Obstetric Problems}

IAN DonalD, M.B.E., M.D. (Lond.), F.R.C.o.G. Third Edition. Pp. xix +811 , illustrated. London: Lloyd-Luke (Medical Books). 1964. 70s.

The author has an easy and interesting style, e.g. he manages in this third edition to make a comparison of the two ways of performing transvaginal pudendal block read more like a description from an exciting novel, than like a dreary text. There are many good new things in this book. The ventouse is well described. The chapter on ante-partum hæmorrhage is excellent, although the speed of progress in obstetric thought has now overtaken Professor Donald's list of causes, because folic acid is not discussed fully as such an important cause as we now believe it to be. Psychoprophylaxis receives adequate mention.

\section{Gynæcology for Senior Students of Nursing}

John Cairney and J. CaIrney. Third edition. Pp. 247, illustrated. Christchurch, New Zealand: N. M. Peryer. 1963. 32s. 6d.

This edition includes for the first time chapters on hormone therapy and sex chromosome abnormalities, both of which are well written, whilst the chapter on contraception has been expanded to include an account of oral contraception. The technique of obtaining cervical smears and cervical cone biopsies is also described. The illustrations are well drawn although Figure 5 should be corrected as it shows the internal os wrongly placed and the lateral fornices non-existent.

\section{An Introduction to Electrocardiography}

L. Schamroth. Pp. $\mathrm{x}+165$, illustrated. 2nd Edition. Oxford: Blackwell Scientific Publications. 1964. 20s.

Dr. Schamroth is perhaps at his best when explaining rather complicated concepts. The genesis of the displaced ST segment in myocardial ischæmia is well described, and after a short perusal of the appropriate diagrams one is left wondering why the mechanism of the electrocardiographic patterns of bundle branch block had hitherto somehow avoided comprehension. Variations in the anatomical heart position and their effects on the electrocardiograph are simply described in diagramatic form. This second edition has been enlarged, and such topics as the Wolff-Parkinson White Syndrome, A-V dissociation and parasystole are now included. Recent work on phasic aberrant ventricular conduction, to which Schamroth has contributed, is particularly well described. 